\title{
Onychopapilloma Presenting as Leukonychia: Case Report and Review of the Literature
}

\author{
Pierre Halteh $^{\mathrm{a}}$ Cynthia Magrob Richard K. Scher ${ }^{\mathrm{a}} \quad$ Shari R. Lipner ${ }^{\mathrm{a}}$ \\ Departments of ${ }^{\mathrm{a}}$ Dermatology and ${ }^{\mathrm{b}}$ Pathology and Laboratory Medicine, Weill Cornell Medicine, New York, N.Y., \\ USA
}

\section{Established Fact}

- Onychopapilloma is a benign nail bed tumor that typically presents clinically as localized longitudinal erythronychia.

\section{Novel Insight}

- Longitudinal leukonychia is now recognized as the second most common presenting sign for onychopapilloma.

\section{Key Words}

Nail · Leukonychia · Onychopapilloma · Nail tumor

\begin{abstract}
Onychopapilloma is a benign tumor of the nail bed and distal matrix and is the most common cause of localized longitudinal erythronychia. Here, we describe a case of onychopapilloma presenting as longitudinal leukonychia of the left 4th fingernail in a 71-year-old female. To date, this is only the ninth described case of onychopapilloma presenting as longitudinal leukonychia. We review the literature on the reported cases and provide evidence that longitudinal leukonychia as the presenting sign for onychopapilloma is becoming increasingly recognized in clinical practice.
\end{abstract}

(c) 2016 S. Karger AG, Basel

\section{KARGER}

E-Mail karger@karger.com

www.karger.com/sad

\section{Introduction}

Onychopapilloma is a benign tumor of the nail bed and distal matrix. It was first reported by Baran and Perrin in 1995 [1] who later expanded the clinical and histological description and coined the term onychopapilloma in the year 2000 [2]. The most common clinical presentation of onychopapilloma is localized longitudinal erythronychia [3]. We report a case of onychopapilloma presenting as longitudinal leukonychia of the left 4th fingernail in a 71-year-old woman and review previous reports.

\section{Case Report}

A 71-year-old female with a past medical history of breast cancer, osteoporosis, and hyperlipidemia presented for evaluation of a white streak on her left 4 th fingernail. She noticed it 3 years ago 
and denied pain, discomfort, or previous trauma. There was a history of brittle nail syndrome diagnosed in 2013 treated with oral biotin. On physical examination, there was a homogenous $1-\mathrm{mm}$ white longitudinal band of the left 4 th fingernail originating from the distal lunula, thereby creating a subtle ridge in the nail plate (fig. 1a). When examined end-on, a keratotic papule was evident at the hyponychium (fig. 1b). Evaluation of the other fingernails and toenails was essentially normal.
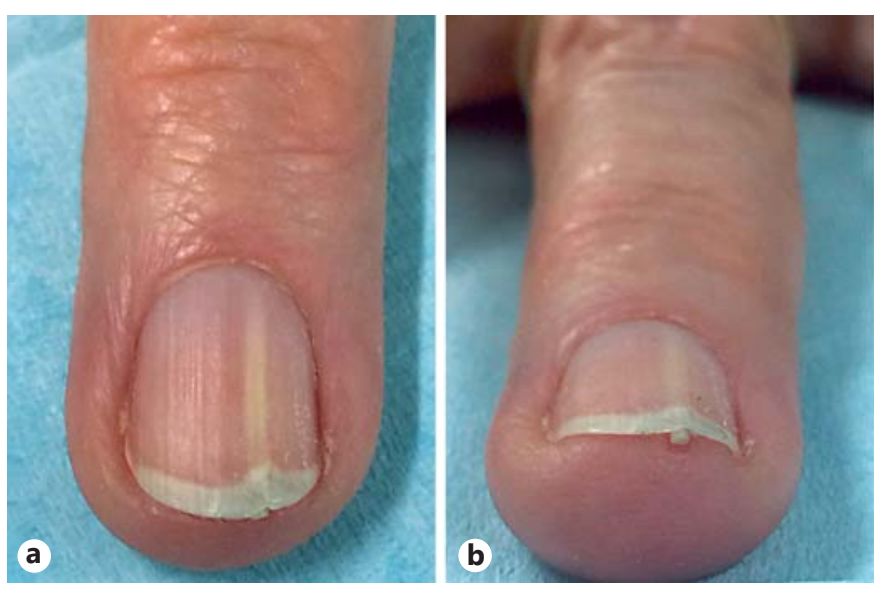

Fig. 1 a Left 4 th fingernail with a $1-\mathrm{mm}$ white longitudinal band originating from the distal lunula with an associated ridge in the nail plate. $\mathbf{b}$ End-on view of left 4 th fingernail with a keratotic papule visible at the hyponychium.
Trap-door avulsion of the nail plate allowed for exploration of the subungual region and revealed a longitudinal ridge extending from the distal nail matrix to the hyponychium. A longitudinal tangential biopsy [3] was performed and sent for histopathology; the nail plate was sutured to the nail bed.

On histopathology, significant abnormalities were not seen in either the nail matrix or hyponychium. The main abnormality was in regards to the nail bed; rather than manifesting a simple, nonstratified epithelium of two to three layers, it was acantholytic and showed a stratified morphology with the most superficial layer exhibiting a keratogenous zone with abundant eosinophilic cytoplasm. It also had a polygonal appearance, which contrasted morphologically with the more basaloid appearing cells defining the lower layers. Therefore, the nail bed exhibited an architectural pattern and cytomorphology reminiscent of the keratogenous zone of the nail matrix consistent with the concept of matrical metaplasia.

\section{Discussion}

Onychopapilloma is a benign tumor of the nail bed and distal matrix and is the most common cause of localized longitudinal erythronychia [4]. It was first reported in 1995 [1] as a localized multinucleate distal subungual keratosis, with distinct clinical and histological features in 4 patients. In 2000, the term onychopapilloma was coined, after describing 14 more cases with comparable clinical and histologic features [2]. Common to these cases was

Table 1. Reported cases of onychopapilloma presenting as longitudinal leukonychia

\begin{tabular}{|c|c|c|c|c|c|c|c|c|}
\hline Authors [ref.] & $\begin{array}{l}\text { Age, } \\
\text { years }\end{array}$ & $\begin{array}{l}\text { Distal } \\
\text { fissure }\end{array}$ & $\begin{array}{l}\text { Subungual } \\
\text { keratotic papule }\end{array}$ & $\begin{array}{l}\text { Splinter } \\
\text { hemorrhage in band }\end{array}$ & Female & Male & Caucasian & Other race \\
\hline Present case & 71 & 0 & 1 & 0 & 1 & - & 1 & - \\
\hline Criscione et al. [6] & 50 & 1 & 1 & 0 & 1 & - & 1 & - \\
\hline Tosti et al. [7] & - & 3 & 7 & 0 & 6 & 1 & 5 & Hispanic (2) \\
\hline
\end{tabular}

Table 2. Clinical presentations of onychopapilloma

\begin{tabular}{llll}
\hline $\begin{array}{l}\text { Longitudinal } \\
\text { erythronychia }\end{array}$ & $\begin{array}{l}\text { Longitudinal } \\
\text { melanonychia }\end{array}$ & $\begin{array}{l}\text { Longitudinal splinter } \\
\text { hemorrhages }\end{array}$ & $\begin{array}{l}\text { Short splinter } \\
\text { hemorrhages }\end{array}$ \\
\hline $\begin{array}{l}\text { Baran and Perrin [1] }(\mathrm{n}=4) \\
\text { Baran and Perrin [2] }(\mathrm{n}=14)\end{array}$ & $\begin{array}{l}\text { Miteva et al. [8] }(\mathrm{n}=1) \\
\text { Ito et al. [9] }(\mathrm{n}=1) \\
\text { Gee et al. [10] }(\mathrm{n}=1)\end{array}$ & Tosti et al. [7] $(\mathrm{n}=4)$ & \\
$\begin{array}{l}\text { Beggs et al. [11] }(\mathrm{n}=1) \\
\text { Tosti et al. [7] }(\mathrm{n}=25)\end{array}$ & & & \\
& Jellinek and Lipner [3] $(\mathrm{n}=41)$ & & 8 \\
\hline
\end{tabular}


that the nail bed epithelium had a superficial eosinophilic layer similar to the nail matrix keratogenous zone, plus acanthosis and papillomatosis of the distal nail bed epithelium. Multinucleated cells were present in some but not all cases $[1,2]$. It is thought that this tumor develops when the distal nail matrix differentiates precociously into nail bed epithelium with formation of a hyperplastic nail bed [5].

The first case of onychopapilloma associated with leukonychia was reported by Criscione et al. [6] in 2010 . It was in a 50-year-old female who had a longitudinal band of leukonychia and a keratotic papule at the hyponychium for several years. There was an associated Vshaped notch and split. The authors hypothesized that the leukonychia was due to metaplasia of the nail bed epithelium causing altered light refraction and fibrosis of the nail bed stroma.

Tosti et al. [7] recently reported on another 7 cases of longitudinal leukonychia as part of their larger report on 47 cases of onychopapilloma. Six patients were female, and 1 patient was male, with 5 Caucasians and 2 Hispanics. Symptom duration ranged from 6 months to 5 years, and there was a subungual keratotic papule in all cases. There were no splinter hemorrhages in any of the bands, and in 3 cases, there was a distal fissure.

This report represents the ninth described case of onychopapilloma presenting as longitudinal leukonychia. It shares similar clinical and histological findings with previous cases, namely a longitudinal white band with a keratotic papule at the hyponychium with acanthosis, papillomatosis, and matrix metaplasia of the nail bed $[1,2]$. Clinical and demographic data for the 9 cases of onychopapilloma presenting as longitudinal leukonychia are shown in table 1 . To date, the majority of cases are reported in Caucasian females aged 50 years and older.
The diagnosis of onychopapilloma can be made from a nail clipping provided it includes the entire distal nail plate. Histopathology shows a localized asymmetric keratotic portion underneath the free edge of the nail, comprised of layered hyperkeratosis [7]. However, a biopsy that includes the matrix and nail bed is required for definitive diagnosis [3]. A biopsy is also necessary to rule out squamous cell carcinoma in situ/Bowen disease; however, it is distinguished from onychopapilloma by the absence of a subungual hyperkeratotic mass [7].

Longitudinal leukonychia, as the presenting sign for onychopapilloma, is becoming increasingly recognized in clinical practice. While longitudinal erythronychia is the most frequent presentation of onychopapilloma, longitudinal leukonychia is the second most common. Other appearances are longitudinal splinter hemorrhages, longitudinal melanonychia, and short splinter hemorrhages, listed in order of decreasing frequency. Table 2 summarizes the different clinical presentations of onychopapilloma.

\section{Statement of Ethics}

Verbal photographic and informed consent was obtained from the patient described in this article.

\section{Disclosure Statement}

Pierre Halteh and Cynthia Magro have no conflicts of interest to disclose. Richard K. Scher has received honoraria while serving as a consultant for multiple companies including Valeant Pharmaceuticals International Inc. Shari R. Lipner has received honoraria while serving as a consultant for Sandoz Pharmaceuticals, Inc.

\section{References}

1 Baran R, Perrin C: Localized multinucleate distal subungual keratosis. Br J Dermatol 1995; 133:77-82.

2 Baran R, Perrin C: Longitudinal erythronychia with distal subungual keratosis: onychopapilloma of the nail bed and Bowen's disease. Br J Dermatol 2000;143:132-135.

3 Jellinek NJ, Lipner SR: Longitudinal erythronychia: retrospective single-center study evaluating differential diagnosis and the likelihood of malignancy. Dermatol Surg 2016;42: 310-319.

4 Collins SC, Cordova K, Jellinek NJ: Alternatives to complete nail plate avulsion. J Am Acad Dermatol 2008;59:619-626.
5 Perrin C: Tumors of the nail unit. A review. Part I: acquired localized longitudinal melanonychia and erythronychia. Am J Dermatopathol 2013;35:621-636.

6 Criscione V, Telang G, Jellinek NJ: Onychopapilloma presenting as longitudinal leukonychia. J Am Acad Dermatol 2010;63:541542.

7 Tosti A, Schneider SL, Ramirez-Quizon MN, Zaiac M, Miteva M: Clinical, dermoscopic, and pathologic features of onychopapilloma: a review of 47 cases. J Am Acad Dermatol 2016;74:521-526.
8 Miteva M, Fanti PA, Romanelli P, Zaiac M, Tosti A: Onychopapilloma presenting as longitudinal melanonychia. J Am Acad Dermatol 2012;66:e242-r243.

9 Ito T, Uchi H, Yamada Y, Oda Y, Furue M: Onychopapilloma manifesting longitudinal melanonychia: a mimic of subungual malignancy. J Dermatol 2015;42:1199-1201.

10 Gee BC, Millard PR, Dawber RP: Onychopapilloma is not a distinct clinicopathological entity. Br J Dermatol 2002;146:156-157.

11 Beggs S, Butala N, Heymann WR, Rubin AI: Onychopapilloma presenting as longitudinal erythronychia in an adolescent. Pediatr Dermatol 2015;32:e173-e174. 